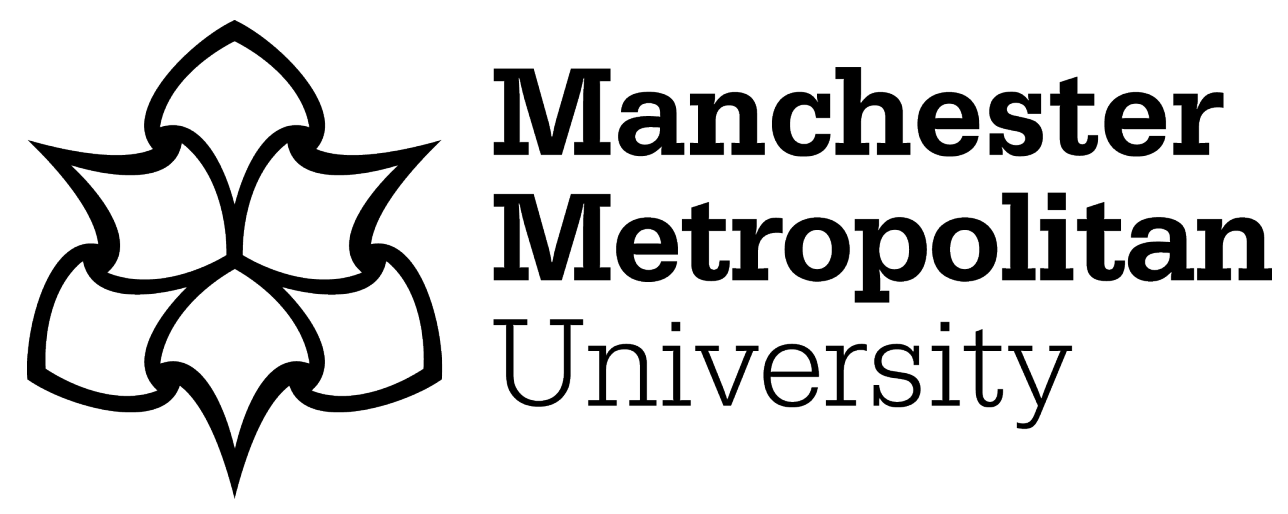

Archer, Dawn and Willcox, P (2018) The faces at play in performance appraisals: With a focus upon a UK retail organization. Journal of Politeness Research, 14 (2). pp. 167-192. ISSN 1612-5681

Downloaded from: https://e-space.mmu.ac.uk/621018/

Version: Accepted Version

Publisher: De Gruyter

DOI: https://doi.org/10.1515/pr-2018-0012

Please cite the published version 


\title{
The faces at play in performance appraisals: With a focus upon a UK retail organization
}

Dawn Archer and Phil Willcox

\begin{abstract}
A variety of face types can be in operation in workplaces, dependent on, for example, the kind of workplace, the various activities engaged in in that workplace, the status/role/gender of participants working in and/or connected with the workplace, etc. This paper offers an adapted version of Archer's (2015) Facework Scale as a means of accounting for the different types of face in evidence in one activity - Performance Appraisals - in one workplace, relating to a UK retail organization. We will show that interlocutors used facework strategies that emphasized different or multiple facets of face on both a professional and personal level (Jagodziński 2013). This includes attempting to safeguard/support their working relationships (Haugh 2013) by managing impressions of self and/or the company (Jones and Pitman 1982) at the same time as maintaining credibility for self and/or other(s) (Bolino et al. 2016). We use our findings to argue that employers and their employees would benefit from having an understanding of face(work), and briefly discuss the training implications for Performance Appraisals if face(work) notions were introduced.
\end{abstract}

Keywords: face, facework, performance appraisal, facework scale, credibility.

\section{Introduction}

In 2017, the Professional Body for HR and Professional Development in the UK, the Chartered Institute of Personnel and Development (henceforth CIPD) conducted research into how Human Resource (HR) professionals align their identities in their work-based contexts. The report suggests that participants tend to move between aligning their identities with their 
profession (i.e., a professional identity) and aligning their identities with the organization or company they work for (i.e., an organizational or company identity). Activities such as Performance Appraisals (PAs) are examples of occasions where respondents commonly align to an organizational or company identity. ${ }^{1}$ Identity is not a fixed entity, in this case. Rather, it is akin to a dynamically negotiated image of self. We can thus liken it to the face an individual might claim based upon what others seem to be assuming about him/her, and the actions or facework $\mathrm{s} /$ he thus engages in "to make what $[\mathrm{s} /$ he is doing consistent with face" (Goffman, 1967: 5). ${ }^{2}$ These actions might involve face enhancement, face maintenance, face damage, or a combination thereof. Facework, within the PA context, has the potential, in turn, to draw upon both social and moral practices (Haugh 2013) and to be shaped by the past and present (by, e.g., pulling on relational histories and participant identities) as well as having implications for the future. PAs typically happen at a prescribed time in a calendar year, for example. During this 'present' point in time, it is the line manager's (henceforth the appraiser's) responsibility to explore a number of areas, with the appraised, which have been deemed to be representative of a six/twelve-month period in the immediate 'past'. This typically includes:

- What goals the appraised has completed/part-achieved (as a means of addressing their level of competence);

\footnotetext{
${ }^{1}$ PAs are core parts of business and management practice in the UK workplace (CIPD: 2017). Indeed, whilst some companies report moving away from the PA (according to the Washington Post), the majority appear to be continuing with this particular activity type. Following Culpeper (2011: 196), we view an activity type to be "a collection of (...) conversational contributions, including speech acts that stand in a particular pragmatic relationship to each other and have become a relatively conventionalized whole". Note that this definition is narrower than Levinson's (1992) original definition, as talk has become an intrinsic part of the encounter.

${ }^{2}$ Although face and identity are not identical (Culpeper, 2011; Kádár and Haugh 2013), they do overlap. Both "relate to 'self'-image (including individual, relational and collective construals of self)", for example, and thus comprise "multiple self-aspects or attributes" (Spencer-Oatey 2007: 644; Archer 2018: 389). Where they differ, according to Spencer-Oatey (2007: 644), is with respect to their attributes, as "face is only associated with attributes that are affectively sensitive to the claimant", that is, with what the claimant "wants others to acknowledge (explicitly or implicitly)" and/or "wants others NOT to ascribe to him/her" (capitalization as in original).
} 
- Whether/the extent to which the appraised has behaved in line with (i.e., adhered to) Company X's expectations of them, given that company's cultural practices and norms;

- How well they have worked with others, relationally speaking, in an effort to achieve these goals;

- How the individual has developed over that time (i.e., the appraised's sense of self/the appraiser's sense of the appraised in this work-based context) (Martin et al. 2010).

Appraised and appraiser might subsequently imagine the next (half) year, so that they can agree goals for this 6-12 month period (i.e., the immediate 'future'). It is worth noting that both appraised and appraiser are tasked with considering identity-impacting elements in respect to the former. The appraised must articulate (his or her beliefs in respect to) how good I am at my job, whether I fit in here, who I am and what I am like. Given the importance of maintaining "credibility in the eyes of others", as part of his or her facework (Gass and Seiter 2015: 90), s/he is likely to resort to impression management as a result: that is, attempt to manage his or her behaviour in order to influence the perceptions of the appraiser (Goffman 1959: 17, Goffman 1959: 22). His or her impression management might be tactically defensive, thereby involving excuse-making, disclaimers, justifications, etc., or tactically assertive, thereby involving ingratiation and/or self-promotion (Tedeschi and Melburg 1984). This brings us to another consideration when investigating PAs: that of power. The appraiser's task of rating the performance of the appraised means they have legitimized power (Emerson 1962). In most cases, they are also the appraised's superior outside of this interaction. This means they not only have the power to help (part-)shape the appraised's identity-at-work, but also impact on his or her future self, given the links between PAs, income (salary/bonus), future promotion(s), etc. The PA activity norms mean, in addition, that it tends to be them asking the questions, probing for more detail and controlling the discussion within the PA itself (cf. Wartenberg's 1990: 5 notions of power to and power 
over). ${ }^{3}$ As Holmes and Stubbe's (2003) note, people can respond in different ways to such authority. For example, they "may challenge, contest, undermine" and "even subvert" it and hence the power underpinning it (Holmes and Stubbe 2003: 7). As will become clear, such challenges need not involve direct or overly confrontational strategies, but they do tend to involve changes in footing. Footing, here, refers to the stance(s) that interlocutors take to both each other and the content of their talk (Goffman 1981: 128, 1981: 155) and, hence, to how they determine/control the mode and frame of a given interaction. If we relate this to a PA, we might note how appraiser and appraised are animating their own words through their talk, thereby simultaneously adopting the role of animator and author. Both will most probably project their "beliefs and commitments (as principals) in the course of the exchange", too, via their social identities (Cordella 2004: 12). Appraiser and appraised can opt to align to the frames that are created by the other, of course. However, they are likely to instigate a different footing when they feel their projected self is somehow at issue. They may not want to continue within a "teasing" or "joking" footing established by their interlocutor, because they feel it undermines them as a professional, for instance (cf. Goffman's [1981] discussion of a US president and a female journalist). Such shifts from one form of talk to another can occur moment to moment as a particular exchange develops, thereby affecting any further contributions each participant makes to the exchange thereafter. Appraiser and appraised might opt to respond by simultaneously adopting the three aforementioned roles of animator, author and principal in a bid to shift the footing again, for example. Alternatively, they might report the words of another author (be it their interlocutor or another participant who is not present) in a way that signals their stance towards the reported words. They might quote what

\footnotetext{
${ }^{3}$ Power to equates to an ability that individuals (temporarily) possess and use; power over, to the hierarchical relationships between individuals which can result in control, dominance, influence, etc. (Wartenberg 1990: 5, Wartenberg 1990: 28).
} 
was said by Y, in order to present it "as a terrible faux pas" (Goodwin 2007: 19), for example.

This paper investigates three PAs undertaken within a UK private sector healthcare organization in November 2014. They have been taken from a larger dataset relating to the opticians' part of the organization. ${ }^{4}$ The organization in question provides national clinical services (in the form of eye checks) and patient specific prescriptions as well as opportunities for customers to purchase lenses, frames or contact lenses. ${ }^{5}$ The line managers discussed in this study - one female (Appraiser A) and one male (Appraiser B) - are experienced appraisers, trained in line management in general and in conducting PA discussions in particular. In this paper, we draw upon Appraiser A's appraisals of P1 (a male) and P2 (a female), and Appraiser B's appraisals of P3 (a female). The primary aim of our study is to explore the different faces that appraisers and appraised adopted as a means of presenting themselves, others ${ }^{6}$, and/or the organization they represent, in a particular light (see Sections 3 and 4).

We believe that it is important to focus on both appraisers and appraised, given the dynamic nature of facework (Arundale 2009): especially where that facework involves changes in footing. Where relevant, we will also discuss the links between facework, selfpresentation, impression management, and credibility. We follow Schlenker's (1980) distinction of self-presentation, as an attempt to manage X's impressions of self, and impression management, as an attempt by $\mathrm{X}$ to manage the impression(s) of another (or others), object(s) or event(s). Our intention is to better assess how a need to have "credibility

\footnotetext{
${ }^{4}$ The total dataset included four PA recordings and was collected by Willcox, as part of his masters-level studies.

${ }^{5}$ An additional head (or support) office provides all of the functions that allow the retail side of the business to trade, including HR support.

${ }^{6}$ Within the transcripts, we have replaced any personal names of fellow colleagues, which participants mention, with $\mathrm{FN}$ in the case of a female name and MN in the case of a male name (thereby protecting their anonymity).
} 
in the eyes of others" (Gass and Seiter 2015: 90) might shape a participants' selfpresentation, impression management and facework. Our interest in such links is not meant to signal that facework, self-presentation and impression management are always undertaken consciously in this activity type. They are not. However, Willcox's experience in this field and the guidance for appraiser and appraised suggests they are likely to be present (CIPD, 2014; ACAS, 2014). We are thus interested in determining the extent to which facework appears to be undertaken more deliberately for self-presentation and impression management purposes in a context such as this, where at least one participant wants to make the best impression possible, and both participants probably want to present themselves in as positive a light as possible (cf. Archer 2018). We consider, in addition, the potential training implications for managers whose workplace remit requires them to undertake such PAs, were face(work) models to be incorporated into these appraisals (Section 6). With this in mind, we begin the paper by explaining Archer's (2015) facework scale (see Section 2), and its relevance when attempting to explain the different types of facework behaviour evident within the PA activity type. As will become clear, one of the strengths of the Facework Scale is that it allows for the possibility that multiple facework goals might be at play in a given interaction (see Sections 2-4; see also Archer 2008, 2015; Haugh 2013). A PA, in its simplest form, is meant to be a discussion between appraiser and appraised (CIPD: 2014; ACAS: 2014). However, our dataset suggests that other colleagues, and especially peers of the appraised, are discussed in ways that are face enhancing and/or face threatening, thereby alluding to the potential importance of third person facework in this context (see Section 5). We thus propose additions to the Facework Scale that are specific to this particular activity type (but which may also be applicable to related activity types) in the section that follows.

\section{Adding types of face to the Facework Scale}


As Figure 1 reveals, Archer's (2015) Facework Scale is designed to capture both faceenhancing acts (FEAs) and face-threatening acts (FTAs) undertaken by a given Speaker (S): be they (i) overt strategies or (ii) strategies which rely upon a level of strategic ambivalence (because of serving multiple goals for $\mathrm{S}$, for example).

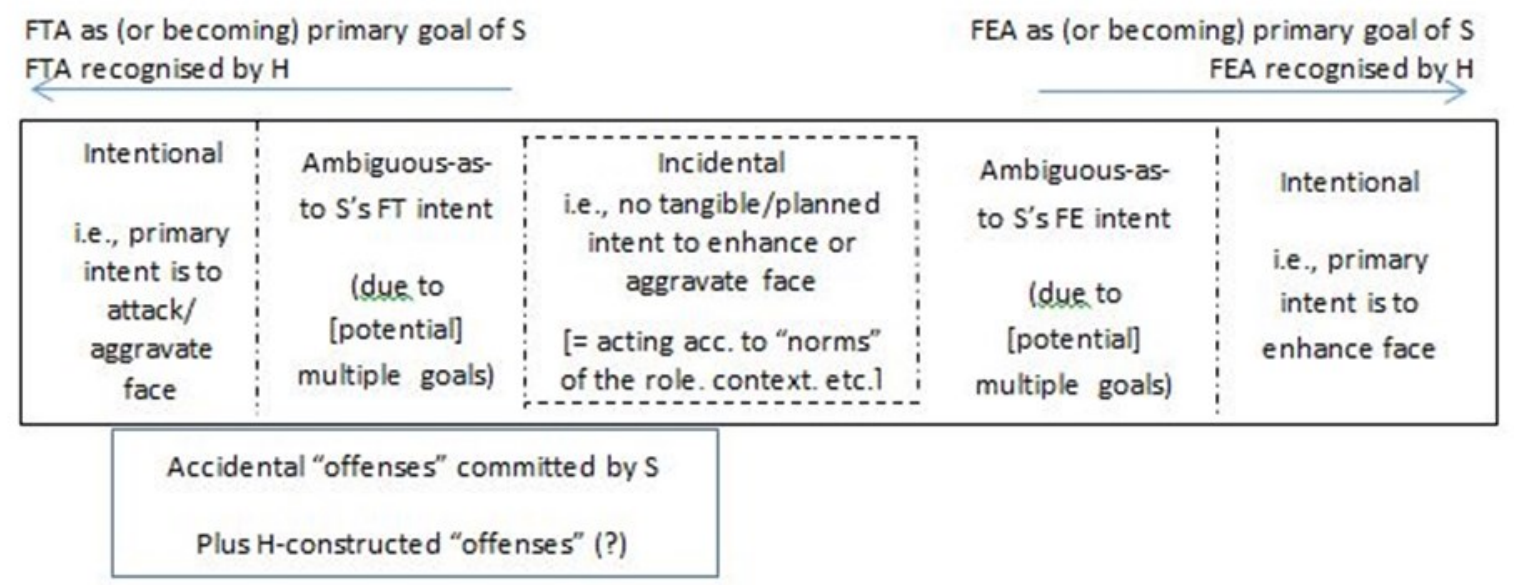

Figure 1: Archer's (2015) Facework Scale

Facework that typifies (i) tends to be of two primary sorts. The facework is deliberately faceenhancing or face-threatening on S's part, thereby falling within the intentional zones of the scale. Alternatively, the facework lacks intentionality, but is still recognized as having the potential to be face damaging or face enhancing for another or others. As such, it equates to an unplanned but nonetheless conceivably anticipatable by-product of an interaction (Goffman 1967: 14) that falls within the incidental zone. ${ }^{7}$ Acts that typify (ii) fall between these intentional and incidental zones, are captured by the two ambiguous zones within the Facework Scale, and enable us to account for:

\footnotetext{
${ }^{7}$ The incidental zone would thus capture what Watts (2003), amongst others, has described as politic behaviour.
} 
- Facework that is ambiguous as to its face-enhancing or face-damaging intent, as well as

- $\quad$ Facework that is designed to achieve multiple facework goals simultaneously.

It is also possible for a given interaction to reflect more than one zone within the Facework Scale (near-)simultaneously, such that the exchange becomes face-enhancing for some and face-damaging for others, for example. Consider (1), where a line manager (LM) compliments (as well as thanks) a female member of his team (FN) in the public setting of a team meeting (for a piece of work they had completed).

(1) Complimenting a job well done ${ }^{8}$

LM Before we get into the meeting agenda okay I'd like to thank FN for her hard work this week. We had some major issues with our output and quality levels and thanks to FN we were able to deliver and hit the numbers .. We really needed that this week so thanks so much .. I know you put in a lot of extra hours so feel free to take the time back on Friday, enjoy the long weekend, you've earned it $=$

FN = thanks boss, it has been full on and yeah if that's OK I'll take time back on Friday

LM excellent, OK, moving on

Most would agree that LM seemed to be engaging in intentional (and direct other-) face enhancement here (assuming the compliment was genuine). The compliment also reflected well upon LM, of course, both in respect to signalling his beneficence and in respect to his overall responsibility for the team: thereby providing potential evidence of indirect self-face

\footnotetext{
${ }^{8}$ The exchange occurred within a team meeting at the same organization as the dataset used in this paper. Willcox was present.
} 
enhancement. It is possible that, when giving the compliment, LM was also suggesting others were not completing their work as well, thereby providing us with evidence of an indirect face attack on his part. Who these others were is unclear and they may or may not have been present in this interaction. Alternatively, it may have been heard as an indirect face threat by those who were present but were not signalled out for praise.

Archer's (2015) Facework Scale is able to account for Hearer $(\mathrm{H})$ meaning in at least two ways:

- In respect to how an FEA or FTA is heard by H (and thus recognized by them to constitute an FEA or FTA on S's part), and

- In respect to how some actions on the part of S can be constructed as being "offensive" by H, whether or not S intended them in this way (cf. Culpeper 2005).

The Facework Scale is also sensitive to the possibility of facework being shaped by the past, present and future, participants' shared knowledge, etc., thanks to Archer's use of zones within a scale, thereby presupposing movement between the zones/across the scale of facework possibilities as an interaction progresses. Extracts like (1) suggest that we need to be able to account for additional possibilities, nonetheless. For example:

(a) Multiple others being present, each of whom may potentially choose to ascribe a different meaning to the face(s) in play, based on their views, opinions or experiences with $\mathrm{S}$, the company/organization, etc.

(b) Third person facework.

In respect to (a) above, note Lim's (1994) observation that different types of face want-such as wanting (i) autonomy, (ii) to be viewed as competent or (iii) fellowship - lead to and can 
thus account for the different interactional uses of facework (as well as self-presentation and impression management strategies) within a given activity type. Relevant face types for a PA include Lim's (1994) fellowship face and competence face (see also Lim and Bowers 1991). Fellowship face relates to the positive image that a person will seek to project, with the aim of being perceived as "likable", "cooperative", "agreeable", etc., by significant others (see also Chen et al, 2006: 153). It thus aligns with some of the identity-related questions highlighted in the Introduction (e.g., whether I fit in here). A closely-related face type, in this regard, is Spencer-Oatey's (2007: 647) relational face, albeit the focus here tends to be upon the management of "the relationship between...participants" as part of rapport work, based upon factors such as the perceived distance-closeness and/or (in)equality between them.

Competence face relates to a person's want to signal and/or be identified with his/her accomplishments, reputation, etc. The person might focus upon his or her experience, capabilities, etc. (cf. Spencer-Oatey's 2002: 540 concept of quality face, which incorporates "appearance" and "abilities" as well as qualities such as "competence"). Competence face, as we understand it, aligns with identity-related questions such as how good I am at my job. If we relate this to Extract (1), above, we might conclude that competence face was the main face in play in this particular extract, albeit that it was initiated by LM, in respect to FN via his face-enhancing approbation/competence message that she had done a good job. It is not the only face type in evidence, however, as LM's indirect enhancement of his own face (as manager over a successful unit) also points to the presence of professional/company face. There is some overlap, in this case, with Spencer-Oatey's (2008: 14) concept of social identity face, albeit the latter relates to all social roles interlocutors adopt, and can thus extend beyond professions to non-professional "group leader", "close friend", etc. (hence our preference for professional/company face). 
Professional face has recently been discussed by researchers such as Jagodziński (2013), who explains that an employee of a company can stand in a metonymic/synecdochical relationship with that company such that s/he not only represents - but becomes - the company for facework purposes. In his work, the employees (call centre agents) were interacting with people from outside the company (callers) so there was no need to separate the company from a profession. Given that the introduction of the 2017 CIPD report talks about the possibility of aligning one's work-based identity to either a professional body or the organization one works for, the distinction between company face and professional face is an important one in the PA context (as Sections 3-5 will make clear). We thus understand company face in this paper to relate to that aspect of an individual's face that identifies (or is identified by others) with the company that employs them. These others may belong to the same company or sit outside the company. Professional face, for us, relates to the extent to which $\mathrm{X}$ identifies themselves and/or others with their profession. As will become clear, what we are labelling personal face is another important facework type in PA settings. Personal face relates to X's identification of self and/or other(s) in a workplace setting beyond their company role or their professional role. An example of facework relating to personal face, in (1), is LM's suggestion to FN that she take the time back on Friday, so that she might enjoy the long weekend, and FN's acknowledgement that she would.

By third person facework - see (b) above - we mean those instances when S mentions to $\mathrm{H}$, be it explicitly or indirectly, others who are not present (for facework purposes). As nonpresent others are not effectively captured in Figure 1, we have created Figure 2 for the reader.

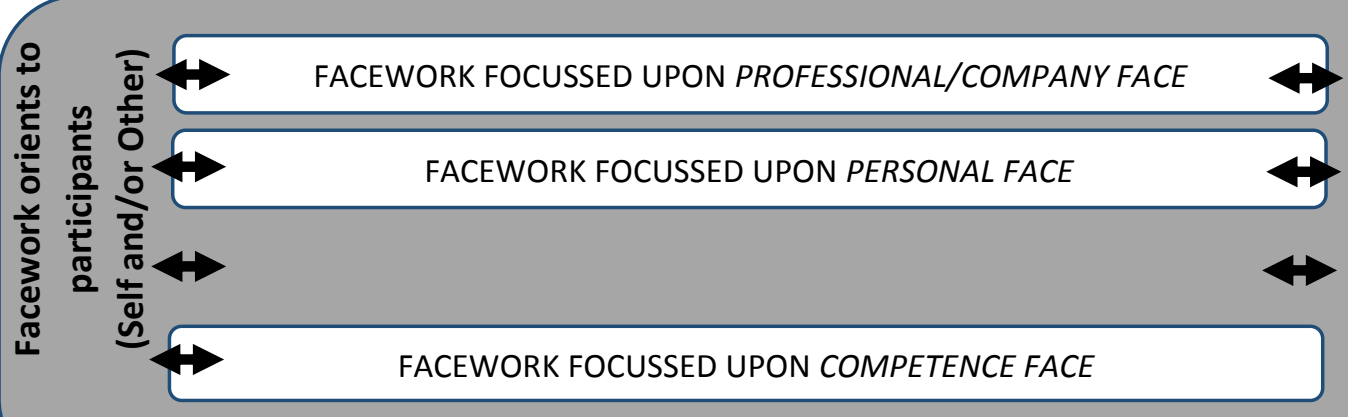




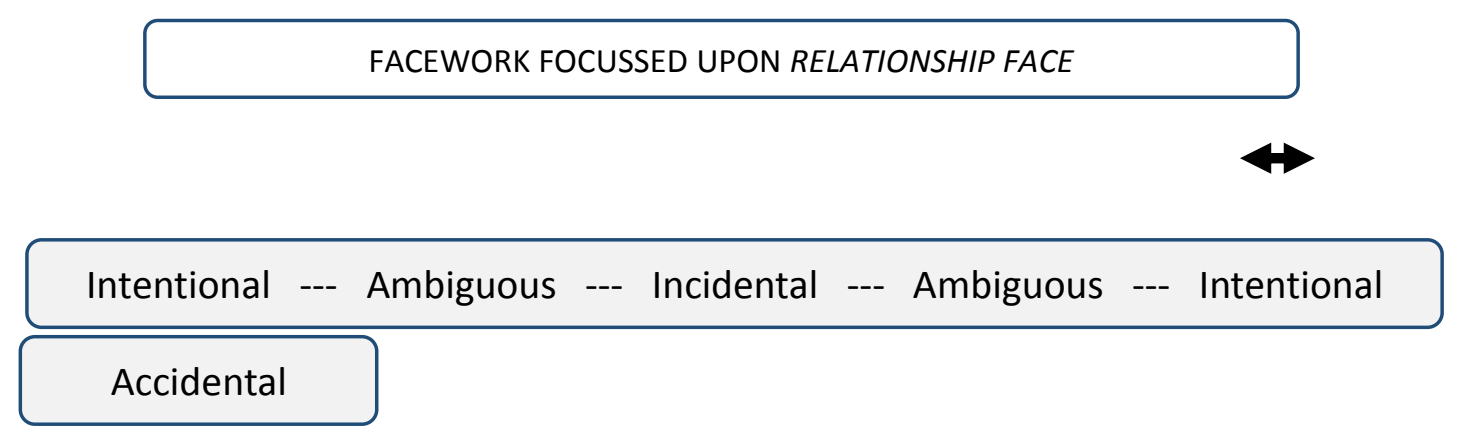

Figure 2: Facework associated with the PA activity type

Figure 2 is designed to be representative of facework which is typically associated with the PA activity type. As Sections 3-5 will highlight, such activity-specific facework can involve face enhancement, face maintenance, face threat or a combination thereof; as captured by the intentional, (strategically) ambiguous and incidental facework zones within Archer's (2015) original scale. These facework zones are replicated as a simplified scale at the bottom of Figure 2, along with the accidental zone (which captures an unintended faux pas by S, as well as FTAs that $\mathrm{H}$ constructs negatively). As facework captured by these zones can be third person oriented as well as participant oriented (Self/Other), and involve different types of face, we situate competence face, relationship face, personal face and professional/company face within the orientation-related facet of our facework model for PAs (see greyed zone above the simplified facework scale). We use the term relationship face deliberately, as a means of signalling that it can potentially combine both fellowship face, as described by Lim (1994), and relational face, as described by Spencer-Oatey (2007) (see above for definitions).

\section{Dealing with multiple facework goals}


Strategic ambiguity is one means by which interlocutors can achieve multiple facework goals. Consider (2), below, which captures P3's response to Appraiser B's question in respect to the organization's new purpose ${ }^{9}$ in the context of the wider business (referred to as 'it' below).

(2) Managing (strategic) ambiguity as to S-intent

B: $\quad<$ breath in $>$ alright $<$ sigh $>$ I suppose do you feel that er within the rest of the . are you hearing it . so where we use it we'll start to use it a little bit more regularly err and that are you hearing it much from elsewhere in the business?

P3: not really I've just been through a session with (MN) doing the briefing so SO

B: yeah great

P3: yeah it was about an hour going through all of that and that's probably the first

B: $<$ sniffs $>\quad$ yeah

P3: time that's happened in a long time so I suppose not going to any of the

B: yeah

P3: leadership events we kind of missed out on that . level so I suppose it's how .

B: $\quad$ Yeah

P3: how do you do that I mean going to today's session great brilliant but it's
B: yeah

P3: almost getting that as well and at the lower levels

B: so there's a case of in effect a piece for me for learning which is what I can bring back from this leadership events but the problem is I have 2 days and then trying to relay 2 days into

P3: I know

B: 2030 minutes of a team meeting it's not $=$

P3: $=$ and I think for me from the team point of view it's good for them to hear it from the top it's quite empowering [...]

\footnotetext{
${ }^{9}$ Building on Simon Sinek's (2011) notion of 'start with why', the Managing Director (MD) began a process that sought to create a company purpose. This purpose expects employees to "commit to enrich the life of every person", and to ensure that this "health led optician...care[s] about a whole lot more". The purpose is currently being used (by company leaders) as a filtering lens, that is, it is meant to initiate conversations such as: Did $X$ deliver the purpose. Yes. Excellent. No. Stop doing it.
} 
Prior to this excerpt, Appraiser B and P3 had been conversing for just over 3 mins, about the implementation of the company purpose in their particular team's part of the business. At the start of the extract, Appraiser B uses alright with a breathing pattern that signals a slight shift in footing from Appraiser/Appraised to that of trusted confidants. He then goes on to ask P3 about how the recently introduced company purpose is being received and, in particular, whether she is hearing it (x2) discussed much, especially from elsewhere in the business. P3 appears to give an immediate response of not really before then going on to share her own personal experiences of a session she recently attended with MN. She also alludes to her no longer going to any of the leadership events (i.e., structured communication and development events organized by the company) before adding I suppose we kind of missed out on that. Readers might find it helpful to know that the level in the hierarchy to which P3 belongs have attended such leadership events historically. This changed, however, following the implementation of the new company purpose, and a related decision to exclude her level of the organizational hierarchy from such events. Due to Willcox's close working relationship with this organization, we know that this decision was interpreted negatively by many at P3's level. This may account for P3's switch from the first person subject singular to the plural: $I$ suppose...we kind of missed out.

Notice that although Appraiser B was positioning P3 as trusted confidante here, his mention of the company's purpose nonetheless alludes to P3's role as middle manager and, in particular, the expectation that she both support and effect its rollout (see footnote9). Given the professional identity implications for $\mathrm{P} 3$, it is not surprising that she opted to first explain that she had only recently had a briefing (of about an hour) and to then emphasize that that was the first time that's happened in a long time. Such a move would be classified as a justification in the impression management literature (DuBrin 2010). As Holland et al. (2002) note, justifications can also include re-frames, which attempt to diminish any aspects that are 
particularly negative. As noted above, P3's particular justification allowed her to focus upon her lack of attendance at the leadership events: albeit without making explicit to whom we was meant to refer (her peer group/management level, the full team, other?). P3 was careful to use a number of mitigating devices (suppose, kind of, I mean, almost) in her response, however, thereby softening what potentially could be heard by Appraiser B as:

(i) Disappointment on P3's part.

(ii) An indirect criticism of Appraiser B for their own line-manager failings.

(iii) Both (i) and (ii).

The focus of the discussion thereafter moved onto Appraiser B's role as line manager. In particular, his remit of either advocating for his wider (managerial) team to attend leadership events or, when not in attendance, to find the most effective means of disseminating the outcomes of such events to the lower levels. Appraiser B opted to deal with this potential face threat by initially evaluating P3's observation as a piece for me for learning, thereby engaging in a level of self-oriented face threat, which had the potential to impact upon his company face, professional face and personal face. This may have prompted Appraiser B's reframing of learning immediately thereafter so that it became a problem supposedly out of his control, because of the time restrictions he faced. Although this allowed Appraiser B to provide a reason/excuse (cf. Edelmann, 1994), as a means of managing impressions, the implications (respecting, e.g., his own time management skills) were potentially damaging to his competence face nonetheless. His use of such tactically defensive impression management strategies (cf. Tedeschi and Melburg, 1984) was also cut short by P3, who sought to iterate explicitly what had only been implied previously up to this point: from the team point of view it's good for them to hear it from the top. $\mathrm{P} 3$ was nonetheless careful to 
provide (once again) her reasoning as justification, this time in a way that appeared to merge the professional and personal faces of her team members: it's quite empowering.

Example (3), below, also picks up on a perceived need to differentiate roles. In this case, however, the appraiser felt compelled to account for and attempt to summarize many different perspectives of a situation, including (but not limited to) the appraised's perspective. To help the reader, the transcript captures P1's assessment as well as Appraiser A's summary of this part of their discussion.

(3) Managing an apparent confusion of roles

P1: part of the problem I think for me doing . things much about this is that they A: $\mathrm{mmm}$

P1: don't work for me em and so if I . you know so I can say . yeah can we get that A Okay

P1: sorted out and they'll say yeah okay . and then . they don't necessarily have to do anything about it em . and . so . I can suggest to well I mean I have mentioned it to them I can I can also mention it to the people who they report to

A: yeah okay uh ha

P1: em and hopefully that all gets sorted out but em

A: okay what else .. what else might help. along the same lines see so if I play it back

P1: $\quad$ er ... don't know ..

A: $\quad<$ breath in and out $>$... what I'm hearing I think is there's been. there's been

P1: $\quad$ yep

A: Been . there's been. a level of . I'm going to call it emm . uncertainty across FN and FN's roles around . which person is accountable for which part

P1: $\quad \mathrm{mmm}$ yes

A: if I sum it up like that . and there is . there is a view on your part . that because neither FN nor FN report into you then in making the request

P1: $\quad$ Mmhhmm

A: of them ... they will still choose I want to or I don't want to do it

P1: $\quad$ well they have the potential to do that yes 
for them to choose . and then you can which . you have done go and have a conversation with . their line manager to say this is what I need

P1: $\mathrm{Mmm}$

A: is there anything else .. that's in your gift to do [...]

$\mathrm{P} 1$ is seeking to identify an ongoing struggle with $\mathrm{FN}$ and $\mathrm{FN}$, which he frames as a problem, occasioned in part by the colleagues in question not working for him. Within this particular utterance, $\mathrm{P} 1$ goes on to make use of numerous hedging and hesitancy devices: they don't necessarily have to do anything about it em. and so. I can suggest to well I mean I have mentioned it to them I can also mention it to the people who they report to. We take this to be indicative of P1's attempt to avoid being seen as someone who lacks the skills to influence others (unless they work for him specifically). The other presentation arguably created face implications for both P1's competence face and professional face nonetheless: by “giving off' the impression that he did, indeed, lack both the authority and managerial skills to make or persuade FN and FN to do as he requested (Goffman, 1959). When Appraiser A summarized P1's suggestion that there had been confusion over the roles of FN and FN in the team, she opted for the term uncertainty in place of problem. The use of the metalinguistic frame, I'm going to call it, and filled pause, emm, prior to uncertainty point to the term being carefully chosen by Appraiser A. As such, we might want to see it as an attempt to reduce the 'weight' of any potential face threat on her part (cf. Brown and Levinson, 1987). The term nonetheless served as a third-person face attack on the un-named line manager(s) who had not undertaken their job effectively enough to prevent such uncertainty. P1's vocal response ( $\mathrm{mmm}$ ) suggests that P1 agreed with the term (as well as the negative assessment of the situation). His affirmative response, Yes, was also significant, given it occurred at the point 
when Appraiser A was stating PI's main contention: which person was accountable for which part (especially when we compare this to his non-committal responses prior to this).

Appraiser A was careful to use both I-statements and you-statements (Shea 2001) throughout her summary, however, such that she carefully distinguished her own sense/thoughts (what I'm hearing I think) from P1's particular view. This points, in turn, to Appraiser A's attempts to engage in incidental facework in this part of the PA. When interlocutors engage in incidental facework, they do not plan to cause face damage deliberately, but are aware that it might be a by-product of their interaction, given the activity type (cf. Goffman 1967: 14). Appraiser A's you-statement to P1 created competence and professional face implications for both him and FN and FN, for example. Indeed, PI was forced to admit verbally what he had only "given off" previously (Goffman 1959): that he did not have the authority or managerial skills to make FN and FN do as he requested. FN and FN were painted, once again, as workers who only did what they had to: to the point of intentionally ignoring a fellow colleague's request. This constituted a third-person threat to their professional face as opposed to their competence face, as P1 was not meaning to imply that they were unable to perform the tasks he was requesting. Rather, his problem was their lack of support for a fellow colleague (him), and how working in that way had the potential to stop the company from achieving its goals. Note, however, Appraiser A's attempts to adjust the footing such that $\mathrm{P} 1$ did not bring an issue without also attempting to provide a solution that went beyond mentioning it to $\mathrm{FN}$ and $\mathrm{FN}$ (as he had done) or possibly mentioning it to the people who they report to (which he had not done up to this point). Hence her yes/no question to $\mathrm{P} 1$ respecting whether there is anything else... things in [his] gift to do at the end of this extract. ${ }^{10}$

\footnotetext{
${ }^{10}$ Some 53 minutes into our recording, Appraiser A went on to signal a level of frustration at P1's propensity to (metaphorically) driv[e] the car looking in the rear view mirror and to focus more on why things can't be done and why things haven't changed.
} 


\section{Multiple goals}

Vonk (1999) and Anderson et al. (2006) suggest that self-deprecating behaviour does not merely have face-saving and/or face-enhancing implications for self and/or other, but also impacts upon (the participants' perceptions of) their likeability, social inclusion, etc. Aspects such as being liked and accepted, perceived as capable, etc., tend to be especially important with regards to PAs. Consider the following self-disclosure(s) in extract (4), below. The extract is taken from Appraiser A's appraisal of P2. At the beginning of the appraisal, P2 disclosed an ongoing condition to Appraiser A: Multiple Sclerosis (MS). She also disclosed that she was pleased with how she had managed her time and performance over the period being appraised, given the impact that MS can have. This positive promotional behaviour, referred to as self-promotion in the impression management literature, is a means by which a speaker can accentuate their competency (see, e.g., DuBrin 2010). In this particular case, it also served the additional function of offering a footing for the PA itself, where P2's workplace self was framed favourably. However, there then followed a prolonged phase of questioning and exploration, led by Appraiser A, in respect to P2's views on asking for help and support from others. Although P2 provided answers to all of the questions, Appraiser A seemed to want more information from P2 than had been proffered. After twelve minutes, P2 resorted to excusing behaviour, which once more brought her MS condition to the fore:

(4) Managing disclosures

A: $[\ldots]$ that's one observation that's one what else about them

P2: $\quad$ yeah $\quad<$ sigh in and out $>$ oh em . you'll have to excuse me I'm a bit slow today <laughs $>$

A:

no don't be silly (FN) don't be silly you're doing really well you're doing really well 
P2: $\quad$ em . <sigh out $>$

yeah

$<$ laughs $>$

A: I want to unpick this I think this is I think this is key

P2: $\quad<$ laughs $>$

.. so what is there about proof

we'll there .. $\quad$ yeah that's evidence and observation

yeah to do

A: $\mathrm{mmm}$

mmhhmm

P2: something em .. ask me again sorry

please

A:

shall I share what's in my head

$<$ laughs $>$

P2: I'm going really muddy today

A:

I'll don't be silly you're doing really well I'll share

what's in my head

$<$ breath in $>$ so .. if I play back what I've heard in the

P2: $<$ laughs $>$

A: last few questions I've asked in the last few few em er sort of reflections that's P2: Okay

A: you've had I guess. I hear from you that em . balance of year we've cracked some

In using the metaphor, slow, $\mathrm{P} 2$ seemed to be intimating that her perceived inability to provide the answers Appraiser A was looking for was because of how her condition was affecting her that day, as opposed to any unwillingness or resistance on her part. Hence her emphasis upon the present, via today. P2's actions potentially fall within Archer's (2015) ambiguous zone, in facework terms, nonetheless. For it is not clear whether - given the 12minute discussion around the topic up to this point $-\mathrm{P} 2$ was now deliberately attempting to curtail the conversation, thereby impacting upon Appraiser A's action-environment (Wartenberg 1990). Although Appraiser A initially opted to enhance P2's positive face in response - by repeating that she was doing really well - she immediately went on to signal her intention to continue (I want to unpick this), thereby impacting on P2's negative face (Brown and Levinson 1987). She was careful to provide a justification for doing so nonetheless (I think this is key). P2 made some effort to continue, before apologizing (sorry), thereby intimating that she was struggling (again). As Archer (2018) notes, apologies are normally used when the apologizer wants to restore the recipient's negative face following a 
transgression (in this case, not being sufficiently articulate). They thus have positive face implications for the transgressor (Brown and Levinson 1987: 187). Appraiser A seemed to hear sorry as a request for help, as opposed to an apology, however. That is, as a supplication, wherein the individual presents herself as 'needy' and thus in need of a sympathetic response (DuBrin 2010: 42). This may help to explain why Appraiser A promptly offered to share what was in [her] head. P2 accepted the offer (please) and then made another (potentially damning) MS-related self-disclosure: I'm going really muddy today. The re-assertion that her cognitive abilities were impaired in the present moment on this particular day, albeit using another metaphor, suggests that P2 was sensitive to any adverse implications respecting her competency (i.e., being able to do her job generally) at this point. Appraiser A's provision of more face enhancement in response is thus interesting, because the implication that she was being silly was designed to be a supportive move (i.e., a

means by which Appraiser A could signal P2 did not need to be concerned). Appraiser A then went on to summarize what she had heard, from P2, in ways that were similarly reassuring: hence words like cracked.

\section{Third person facework}

According to both ACAS (2014) and the CIPD (2014), a PA discussion is focussed upon the appraised's personal performance and/or development. Other colleagues can sometimes be mentioned too, however, and in ways that can be face-threatening as well as face-enhancing (for them as well as the appraised). In (5) following, we have evidence of what might be termed third person deprecation for example (i.e., the undervaluing/criticism/denigration of non-present individuals for facework purposes). 
(5) Emphatic intentional face enhancement via intentional face threat of third party

A : $[\ldots]$ the second thing for me then is . where you have demonstrated and I have to say $(\mathrm{MN})$ you have demonstrated over and beyond probably any other member of the team . the ability to work across functionally this year and I really don't want you to underestimate . you know . how important how impactful and what a huge $<$ laugh $>$ what a huge step that is . you've demonstrated that bigger and bolder than anybody . you really have. I want you to use that experience . now across our function . to help to share those learnings with the rest of the team

A: so demonstrate by example. why you need to do. with our team what you've done with (MN)'s team . to demonstrate the benefits demonstrate the effectivity demonstrate how much easier it makes everybody's life . quite simply by . pulling together sharing insight asking questions of each other and making sure everyone's signed up to .. one view one direction one plan

and and and P1: mmm okay

A: I really think you are so well placed to be able to do that .. and I know . I know it will make others' lives easier and even beyond that I have no doubt it will start to lift some of that weight off your shoulders . of . things are just the same as they've always been because that puts you in a place of empowerment

P: $\quad$ mmm $<$ laughs $>$

A: to be able to change that and take it forward and shape it as you see is right to shape it how does that make you feel

P1: $\quad$ mmhhmm . okay ... right $<$ laugh $>\quad$ okay yeah

A: up for the challenge

P1:

yeah . well you know me I don't get excited about anything

A: <laughs $>\quad$ I think you'd forget the enthusiastic

P1: $\quad$ it's not what I do $<$ laughs $>$

A: $\quad$ response $<$ laughs $>$

P1: $\quad<$ laughs $>$ well yeah well this is about as enthusiastic as I get $<$ laughs $>$

A: I know I'm feeling very encouraged em . good okay fab . but I

P1: $\mathrm{Mmm}$

A: think em you know honestly (MN) I think em .. you have . you know you have really . you have really as far as the other teams have gone stepped out of the box this year and and you have demonstrated a way of working that was not only desperately needed . but that others .. hadn't taken the step before you to do and I think you should be really . mindful of that 
the last question. would be just to sort of seek if you had any feedback from me and and most specifically things that . you you . need from me that I don't currently give or . equally things you get from me that you definitely don't need $<$ laugh $>$

Appraiser A's main purpose in this part of the PA (including immediately prior to this extract) was to summarize the discussion thus far and to make two observations. The first observation, not captured above, related to what was needed (from her perspective) for the remainder of the year. The second, as shown above, accentuated P1's main strength: his ability to work collaboratively with others. This second observation had already been raised previously by Appraiser A, and was reinforced here via repetition. P1's strength was initially framed as an achievement that was over and beyond probably any other member of the team for example, thereby enhancing his competence and company face. Following this attempt at impression management, Appraiser A made known that she wanted P1 to share his experience with these colleagues, thereby enhancing his professional face. As P1's response was minimal initially (mmhhmm), Appraiser A stressed her belief that it would serve dual purposes: that of empowering others whilst making their lives easier, and alleviating some of the weight currently upon P1's shoulders (thereby once again engaging in impression management). She also engaged in facework designed to enhance P1's competence face, albeit at the expense of denigrating the competence face of those specific (non-present) colleagues (known to Appraiser A and P1) who needed his expertise. See, especially, her comment in respect to $\mathrm{P} 1$ having demonstrated a way of working that was not only desperately needed. but that others were failing to do, in part because they hadn't taken the step up to this point. Additional face enhancement strategies undertaken by Appraiser A included using positive affect (don't... underestimate, important, impactful) and 
exaggeration (bigger and bolder than anybody, you really have) (see, e.g., Labov 1972;

Brown and Levinson 1987; Tannen 2007; Lakoff and Johnson 2008).

Appraiser A's use of multiple facework strategies to get P1 to accept the line (Goffman 1967) respecting his ability to work collaboratively (complimenting using repetition, exaggeration, etc.) points to the importance of considering the preferred face type(s) of the appraised when planning for PAs: something we will pick up on in Section 6. Suffice it to say, P1 seemed to be at pains to point out that he did not engage in outward displays of enthusiasm (and in ways that drew upon his personal face). Hence self-disclosures such as this is about as enthusiastic as I get. Appraiser A's semi-jokey response, I know I'm feeling very encouraged suggests she found P1's lack of responsiveness a little disconcerting. This was perhaps because she had anticipated that her overt face enhancement would enhance P1's (and hence, implicitly, her own) relationship face (in giving the FEA) as well as her professional face (as a good line manager/appraiser). We might note in addition that Appraiser A's face enhancement was linked to her request. As such, P1 might have determined that, by accepting the face enhancement enthusiastically, he was also somehow agreeing to the request (enthusiastically). ${ }^{11}$

Example (5) above was not an isolated example of intentional face enhancement via intentional face threat of a third party. In (6) below, Appraiser B used the same strategy during his PA with P3 (albeit for different reasons).

(6) A metaphorical pat on the back

\footnotetext{
${ }^{11}$ A number of researchers have pointed out the important inter-relationship between face and affect (see, e.g., Goffman 1967; Culpeper 2011). This inter-relationship is arguably especially important for PAs because of the three aspects at play, namely, the need to summarize (1) the past (especially what has happened over the previous 6-12 months period), (2) the present (the PA itself) and (3) the future (especially what is to come over the next 612 month period) (see Introduction).
} 
B: alright a good thing is here I've got a note against $\mathrm{MN}$ to talk about time management

P3: <laughs $>$

B: and attention to detail I don't have to speak to you about that thankfully em .. I've not . I've specifically this time around not gone for feedback of others . because what I'm seeing and the general conversation around everywhere . is really really good place so you ought to really take a pat on the back for this . this I think if it hadn't have been for the [Company] brand . original order issue we would've been covering everything so

P3: $\quad \mathrm{Mmm}$

B: $\quad$ so I've got to say my own view is is what's happened over the last 6 to 8 weeks is not in terms of crashing into us saying what are you doing about availability isn't about us it's about a business issue however . the right thing was dealing with that because we've in effect said

Prior to this exchange, Appraiser B had discussed with P3 his summary of her growth and personal development over the year thus far. Appraiser B's alright then served to signal a change in footing to a different topic of conversation, which framed what was to come as ' $a$ good thing', thereby setting up an expectation, in P3, that some form of face enhancement was to follow. This face enhancement was implicit, however: for Appraiser B went on to introduce a non-present colleague (MN) into the PA, in order to criticize MN's time management and attention to detail, thereby attacking his competence face. As in (5), then, we have evidence of an appraiser using comparison as a way of achieving face enhancement, as signalled by his comment, 'I don't have to speak to you about that thankfully'. Notice that this particular utterance had the potential to serve multiple goals in facework terms. It provided a means of signalling that $\mathrm{P} 3$ does not demonstrate the undesirable attributes mentioned, for example, and thus that Appraiser B had not been put in the unfortunate position of having to deliver such 'bad news' to P3 (as he might have to, to MN for example). This would serve to enhance the relationship face of both, as well as the competence face of P3. It also provided P3 with important knowledge: namely, that Appraiser B would not want to have to speak to P3 about such things in the future. It had implications, in turn, for Appraiser B's own competence and/or company face, especially when considered alongside 
his disclosure to $\mathrm{P} 3$ that he had a note to talk to $\mathrm{MN}$ (and hence took his management responsibilities seriously). ${ }^{12}$

Appraiser B went on to evaluate P3's place of work positively (really really good), and attributed much of that to P3 (you ought to really take a pat on the back for this), thereby explicitly enhancing her competence face and arguably her personal face. He also excused her (and, by implication, him) from any mistakes that had been made in the previous 6 to 8 weeks, by explicitly asserting that what she was doing about availability was not about them but, rather, a business issue (thereby bringing into play her professional as opposed to company face). By so doing, Appraiser B effectively positioned himself and P3 within the us of an "us versus them" dichotomy, in ways that were potentially face-damaging for the company.

\section{Concluding comments, and training implications for managers}

This paper began with a summary of the PA (see Introduction). Drawing upon Goffman (1967: 5), as our starting point, we suggested that PAs involve lines - or, more appropriately for our purposes, different types of face - which individuals claim and/or (re)negotiate based upon what others seem to be assuming about them. As well as drawing upon existing practices within a given company, these faces tend to be shaped by the past and present as well as having implications for the future. PAs typically happen at a prescribed time in the calendar year, during which appraiser and appraised explore a number of areas representative of a six/twelve-month period in 'the past' as well as a future period of similar length. We identified the most typical face types in operation in such PAs in Section 2, based on a dataset collected by Willcox. These were competence face, personal face, professional/company face

\footnotetext{
${ }^{12}$ We can confirm that Appraiser B did speak to MN about this issue, in MN's own appraisal (not included here).
} 
and relationship face. We then went on to locate these face types within an orientation space: thereby allowing us to distinguish between facework that is aimed at participants who are present (self and/or other), and facework that is third-person oriented (see Figure 2). As Figure 2 revealed, these activity-specific face types were then incorporated into Archer's Facework Scale (as explained in Section 2).

In Sections 3-5, we went on to demonstrate how our revised model might be used to analyze facework in the PA context, and (where relevant) identified the links between their chosen facework techniques and self-presentation/impression management. An obvious link between the latter and facework, evident in all our extracts, was the desire to make the best impression possible (compare, especially, [2] and [3]). This was often linked to or manifested as competence face: something that could be anticipated, to a certain extent, given the function of PAs (i.e., appraising performance in a workplace context). This helps to explain why the facework undertaken by each of our appraisers tended to be face-enhancing and/or face-maintaining in respect to the appraised, in the main. However, as extracts (2) to (6) clearly reveal, the PAs could also (and often did prove to) have face-threatening elements: sometimes for the appraised, and sometimes for the appraised's non-present colleagues. This could (and did) create face issues for the appraisers, in turn.

Our analyses of extracts (2) to (6), taken from actual PAs undertaken within a UK retail organization, clearly indicate that face types other than competence face were also commonly at play, and often simultaneously, in this particular context, not least because of the topics typically discussed (what X has done, how X has done it, etc.). As with competence face, those faces impacted upon, and/or were related to, non-present colleagues in addition to those who were present. In fact, facework by means of reference to a non-present colleague was found to be a common feature across the PA interaction analyzed here (as well as the wider dataset that Willcox collected as part of his postgraduate studies). In the examples 
reported here, appraisers used deprecation of a third party in order to enhance the faces of the appraised: see especially (5) and (6). It is worth noting that this way of giving compliments, recognizing strengths and hard work, etc., is absent from any published guidance by the CIPD (the HR professional body) or the Advisory, Conciliation, and Arbitration Service (ACAS). ${ }^{13}$ Such an approach does not feature as a practice to avoid either. This might mean that the practice is unique to the organization under study or, alternatively, that it is a wide(r) practice, albeit one that remains undocumented to date. Additional research, focusing on the PAs of other organizations (representative of different sectors) would thus be valuable.

Our ability to distinguish different face types should not be taken to mean that the appraisers and appraised were aware of these face types and/or their facework activity in the way that is reported here. They were not. This brings us to the final aim(s) of this paper:

- That of determining whether there is anything to be gained were those taking part in PAs to know about face types and facework: and, relatedly,

- The potential training implications for managers whose workplace remit requires them to undertake such PAs, were face(work) models to be incorporated into their appraisals.

We have proposed that specific face types are salient in this activity type, and in ways that have a bearing on the success (or not) of a PA. We are sensitive, nonetheless, to the fact that these (as well as other) appraisers have been completing PAs for many years with no conscious or deliberate training in respect to the role played by face(work). Moreover, while there seems to be a movement, currently, towards changing or evolving the approach to PAs

\footnotetext{
${ }^{13}$ ACAS "provide(s) information, advice, training, conciliation and other services for employers and employees to help prevent or resolve workplace problems." For details, see http://www.acas.org.uk/index.aspx?articleid=1461
} 
(see Section 1), we see no value in adding something to the training that serves to overcomplicate the interaction and thus negatively affect the (overall approach to the) PA. This explains our attempts to devise a model, which is specific to the PA context (see Figure 2). We believe further, that, were appraisers to be aware of the typical face types that occur in the PA activity type, they would be able to use that knowledge when determining the best means of framing their feedback (including whether it was appropriate to tailor their approach to the dominant face type of the appraised). Consider Appraiser A and P1 in (5). Appraiser A was effusive in her praise of $\mathrm{P} 1$, who seemed at pains to point out that he did not engage in outward displays of enthusiasm. Appraiser A might have used this knowledge (especially if it were prior knowledge) to consider additional ways of interacting with P1 (especially when requesting that $\mathrm{P} 1$ help others). Additional possibilities include appraisers using the knowledge of face types and facework (i) to reduce misunderstandings or miscommunications by reducing ambiguity and increasing clarity/transparency, (ii) to achieve greater agreement in respect to past/present/future performance.

Being able to identify dominant face types may also be beneficial for the appraised. For example, it may help them when considering the comments from appraisers and/or to understand which type(s) of face were at play for the latter as well as for them. They (and the appraiser) would also be able to discern the extent to which they were identifying with a company and/or with their own personal goals (as signalled by the dominance of one of three faces: company face, professional face or personal face). Given face and facework are a feature of all interactions (Held 2014: 60), any training relating to such aspects has the potential to extend beyond the PA activity type too. This might be useful when conversations are taking place between line managers and their team members, and/or when interacting with peers of similar status, for example. 


\section{References}

ACAS, 2014. How to manage Performance. Advisory booklet [on line]. Available at http://www.acas.org.uk/media/pdf/m/0/How-to-manage-performance-advisorybooklet.pdf. Accessed 1 May 2015.

Anderson, Cameron, Sanjay Srivastava, Jennifer S. Beer, Sandra E. Spataro \& Jennifer A. Chatman. 2006. Knowing your place: Self-perceptions of status in face-to-face groups. Journal of Personality and Social Psychology 91(6). 1094-1110.

Archer, Dawn. 2008. Verbal aggression and impoliteness: Related or synonymous? In Derek Bousfield \& Miriam Locher (eds.) Impoliteness in language. (Language, Power and Social Processes Series), 181-207. Berlin and New York: Mouton de Gruyter.

Archer, Dawn. 2015. Slurs, insults, (backhanded) compliments and other strategic facework moves. Language Sciences 52. 82-97.

Archer, Dawn. 2018. Impression management in the Early Modern English courtroom. In Merja Kytö \& Terry Walker (eds.). Dialogues in diachrony. [Special issue]. Journal of Historical Pragmatics. 19(2): (not yet paginated).

Arundale, Robert B. 2009. Face as emergent in interpersonal communication: An alternative to Goffman. In Francesca Bargiela-Chappini \& Michael Haugh (eds.), Face, communication and social Interaction, 33-54. London: Equinox.

Bolino, Mark, David Long \& William Turnley. 2016. Impression management in organizations: Critical questions, answers, and areas for future research. Annual Review of Organizational Psychology and Organizational Behavior 3. 377-406.

Brown, Penelope \& Steven C. Levinson. 1987, Politeness: Some universals in language usage. Cambridge University Press. 
Chen, Serena, Helen C. Boucher \& Molly Parker Tapas. 2006. The relational self revealed: Integrative conceptualization and implications for interpersonal life. Psychological Bulletin 123(2). 151-179.

CIPD. 2014. Performance Appraisal Factsheet [online]. Available at http://www.cipd.co.uk/hr-resources/factsheets/performance-appraisal.aspx. (Accessed 28 July 2014)

CIPD. 2017. 'HR Professionalism: What do we stand for?' Research Report [online]. Available at https://www.cipd.co.uk/Images/hr-professionalism-what-do-we-standfor_2017_tcm18-17960.pdf. (Accessed 28 July 2017).

Cordella, Marisa. 2004. The dynamic consultation: A discourse analytical study of doctor patient communication. Amsterdam and Philadelphia: John Benjamins.

Culpeper, Jonathan. 2005. Impoliteness and entertainment in the television quiz show: The Weakest Link. Journal of Politeness Research: Language, Behaviour, Culture 1(1). $35-72$.

Culpeper, Jonathan. 2011. Impoliteness: Using language to cause offence. Cambridge: Cambridge University Press.

DuBrin, Andrew J. 2010. Impression management in the workplace: Research, theory and practice. New York: Routledge.

Edelmann, Robert J. 1994. Embarrassment and blushing: Factors influencing face-saving strategies. In: Stella Ting-Toomey (ed.), The Challenge of Facework: Cross-cultural and interpersonal issues, 231-268. New York: State University of New York Press.

Emerson, Richard M. 1962. Power-dependence relations. American Sociological Review 27(1). 31-41. 
Gass, Robert H. \& John S. Seiter. 2015. Persuasion: Social influence and compliance gaining, 5th edn. London and New York: Routledge.

Goffman, Erving. 1959. The presentation of self in everyday life. New York: Doubleday Anchor Books.

Goffman, Erving. 1967. Interaction ritual. Essays in face-to-face behavior. Chicago: Aldine.

Goffman, Erving. 1981. Footing. In Erving Goffman (ed.), Forms of talk, 124-159. Philadelphia: University of Pennsylvania Press.

Goodwin, Charles. 2007. Interactive footing. In Elizabeth Holt \& Rebecca Clift (eds.), Reporting talk: Reported speech in interaction, 16-46. Cambridge: Cambridge University Press

Haugh, Michael. 2013. Disentangling face, facework and im/politeness. Sociocultural Pragmatics 1(1). 46-73.

Held, Gudrun. 2014. Figura...or Face? Reflections on two sociopragmatic key concepts in the light of a recent media conflict between Italians and Germans and its negotiation in Italian internet forums. In Kristina Bedjis, Gudrun Held \& Christiane Maaß (eds.), Facework and social media, 31-62. Berlin: LIT Verlag Münster.

Holland, Rob W., Ree Meertens \& Mark Van Vugt. 2002. Dissonance on the road: Selfesteem as a moderator of internal and external self-justification strategies. Personality and Social Psychology Bulletin 28(12).1713-1724.

Holmes, Janet, \& Maria Stubbe. 2003. Power and politeness in the workplace: A sociolinguistic analysis of talk at work. London: Longman.

Jagodziński, Piotr. 2013. Impoliteness strategies in a British airline call centre: A pragmatic analysis of customer service interactions. Adam Mickiewicz University $\mathrm{PhD}$ thesis. 
Jones, Edward E. \& Thane Pittman. 1982. Toward a general theory of strategic selfpresentation. In Jerry Sules (ed.), Psychological perspectives on the self, 231-262. Hillsdale, NJ: Lawrence Erlbaum.

Kádár, Dániel. \& Michael Haugh. 2013. Understanding politeness. Cambridge: Cambridge University Press.

Labov, William. 1972. Sociolinguistic patterns. Philadelphia: University of Pennsylvania Press.

Lakoff, George \& Mark Johnson. 2008. Metaphors we live by. Chicago and London: University of Chicago Press.

Levinson, Steven C. 1992. Activity types and language. In Paul Drew \& John Heritage (eds.), Talk at work: Interaction in institutional settings, 66-100. Cambridge: Cambridge University Press.

Lim, Tae-Seop \& John W. Bowers. 1991. Facework solidarity, approbation, and tact. Human Communication Research 17(3). 415-450.

Lim, Tae-Seop. 1994. Facework and interpersonal relationships. In: Stella Ting-Toomey (ed.), The Challenge of Facework: Cross-cultural and interpersonal issues, 209-229. New York: State University of New York Press.

Martin, Malcolm, Fiona Whiting \&Tricia Jackson. 2010. Human resource practice. London: Chartered Institute of Personnel and Development.

Schlenker, Barry R. 1980. Impression management: The self-concept, social identity, and interpersonal relationships. Monterey, CA: Brooks/Cole.

Shea, Gordon. 2001. How to develop successful mentor behaviors. Seattle and Washington: Thomas Crisp Learning. 
Sinek, Simon. 2011. Start with why: How great leaders inspire everyone to take action. London: Penguin.

Spencer-Oatey, Helen D. 2002. Managing rapport in talk: Using rapport sensitive incidents to explore the motivational concerns underlying the management of relations. Journal of Pragmatics 34: 529-545.

Spencer-Oatey, Helen D. 2007. Theories of identity and the analysis of face. Journal of Pragmatics 39(4). 639-656.

Spencer-Oatey, Helen D. 2008. Face, (im)politeness and rapport. In Helen Spencer-Oatey (ed.), Culturally speaking: Culture, communication and politeness theory. $2^{\text {nd }}$ edn., 11-47. London: Continuum.

Tannen, Deborah. 2007. Talking voices: Repetition, dialogue, and imagery in conversational discourse. Cambridge: Cambridge University Press.

Tedeschi, James T. \& Valerie Melburg. 1984. Impression management and influence in the organization. In Samuel B. Bacharach \& Edward J. Lawler (eds.), Research in the sociology of organizations, 31-58. Greenwich, CT: JA.

Vonk, Ross. 1999. Impression formation and impression management: Motives, traits, and likeability inferred from self-promoting and self-deprecating behavior. Social Cognition 17(4). 390-412.

Wartenberg, Thomas E. 1990. The Forms of power: From domination to transformation. Philadelphia: Temple University Press.

Watts, Richard J. 2003. Politeness. Cambridge: Cambridge University Press. 